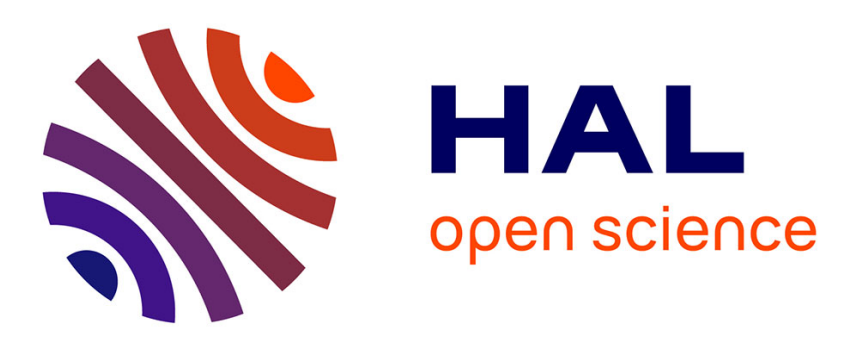

\title{
Is the link between autistic traits and ability to succeed in science independent of other psychopathological dimensions?
}

\author{
Patrick Raynal, T. Melioli, N. Goutaudier, H. Chabrol
}

\section{To cite this version:}

Patrick Raynal, T. Melioli, N. Goutaudier, H. Chabrol. Is the link between autistic traits and ability to succeed in science independent of other psychopathological dimensions?. European Review of Applied Psychology / Revue Européenne de Psychologie Appliquée, 2016, 66 (6), pp.301-307. 10.1016/j.erap.2016.05.004 . hal-03193813

\section{HAL Id: hal-03193813 \\ https://hal.science/hal-03193813}

Submitted on 9 Apr 2021

HAL is a multi-disciplinary open access archive for the deposit and dissemination of scientific research documents, whether they are published or not. The documents may come from teaching and research institutions in France or abroad, or from public or private research centers.
L'archive ouverte pluridisciplinaire HAL, est destinée au dépôt et à la diffusion de documents scientifiques de niveau recherche, publiés ou non, émanant des établissements d'enseignement et de recherche français ou étrangers, des laboratoires publics ou privés. 
Running title : REEXAMINING PERSONALITY IN SCIENCE STUDENTS

Is the link between autistic traits and ability to succeed in science independent of other psychopathological dimensions?

Raynal P., Melioli T., Goutaudier N., Chabrol H.

Département de Psychopathologie Clinique, de Psychologie de la Santé et de Neurosciences

Octogone - Centre d'Etudes et de Recherches en Psychopathologie Université de Toulouse-Jean Jaurès, Toulouse, France 
Corresponding author: Patrick Raynal, Ph.D.

OCTOGONE-CERPP, Université de Toulouse-2-Jean Jaurès, 5 allées Antonio Machado, 31058 Toulouse, France

Phone: +33 619103173

Fax: +33561504918

E-mail: patrick.raynal@inserm.fr 
Introduction : Besides the well-established link between autistic traits and scientific skills, the role of personality in students involved in science has not been thoroughly examined.

Objective: This study aimed at reexamining the link between scientific aptitudes and personality, by considering autistic features and other psychopathological dimensions.

Method: 294 individuals from French scientific universities answered questionnaires assessing autistic, schizotypal and bipolar dimensions, as well as depressive symptomatogy and other variables.

Results: A cluster analysis led to the identification of 4 different groups, among which a cluster was characterized by high scores in autistic, schizotypal and bipolar dimensions. This group, representing nearly $30 \%$ of the sample, displayed higher level of depression symptoms $(M=28.5, S D=12.0)$ in comparison with other groups $(M=11.7$ to $19.1, S D=5.4$ to 9.2). Moreover, the suicidal ideation score was much more important in this cluster $(M=1.6, S D=2.3)$ than in the three other groups $(M=0.1$ to $0.5, S D=0.3$ to 1.3$)$. This suggested that autistic features, when associated with other personality traits, interfere negatively with the ability of individuals to succeed in science studies, which was partly confirmed by comparing the academic level and results of the different clusters.

Conclusion: One may reconsider the link between elevated autistic traits and the ability to accomplish science studies, considering that autistic features are thus frequently associated with other psychopathological traits which may, altogether, lead to depression or other comorbidities negatively interfering with the accomplishment of an academic cursus.

Keywords: Autistic traits, schizotypy, bipolarity, personality, depression. 


\section{Introduction}

It is well accepted that personality plays an important role in the interest and aptitudes of individuals for science (Feist, 2006). A major contribution in this field was brought by studies describing that traits associated with autistic disorders have a pivotal influence on the scientific abilities of individuals. The existence of this link was initially based on the observation of higher frequency of autism cases in families of students involved in mathematics, physics or engineering, in comparison with families of individuals studying literature or humanities (Baron-Cohen et al., 1998; BaronCohen, Wheelwright, Burtenshaw, \& Hobson, 2007). Subsequently, college students involved in scientific programs were found to display more pronounced features of autistic personality than pairs studying literature or social sciences (Baron-Cohen, Wheelwright, Skinner, Martin, \& Clubley, 2001).

Since these studies were released, the question of how personality influences scientific aptitudes has remained quite open. Nervertheless, it was shown that empathy or schizotypy were more dominant in students involved in humanities than in scientific students (Nettle, 2006; Rawlings \& Locarnini, 2008), those latter being characterized by a more pronounced "systematizing" dimension (i.e., an ability to handle different kinds of systems: mechanical, organizable, abstract... Wakabayashi et al., 2006). However, recent data suggested that this systematizing dimension did not automatically correlate with the performance of individuals, notably in the domain of mathematics which represents a typical abstract system (Morsanyi, Primi, Handley, Chiesi, \& Galli, 2012). Moreover, the idea of a lesser schizotypy in scientists may seem somewhat paradoxical, considering that abundant evidences indicate that schizotypal traits are strongly linked with aptitudes for creativity (Fink et al., 2013; MacPherson \& Kelly, 2011; Nelson \& Rawlings, 2009; Rawlings \& Locarnini, 2008). And creativity can be hardly dissociated 
from the ability to achieve scientific discoveries, notably when they involved unexpected findings through the so-called serendipity (cf. the discovery of penicillin or the medical use of X rays) (Rosenman, 1988; Stoskopf, 2005; Yewdell, 2008).

Another link between personality and scientific abilities was brought to light by research groups studying the psychological profile of high school students. Indeed they observed that individuals with the highest grades in mathematics had a strong level of perseverance and low distractibility (Guerin, Gottfried, Oliver, \& Thomas, 1994). More recently, other authors reported that high school students with a significant level of inhibition (shyness, apprehension of socializing with unknown individuals...) obtained better performance in mathematics, due to the fact that these students were less prone to participate in social activities inappropriate for learning mathematics (e.g., chit-chat) (Hintsanen et al., 2012).

Nevertheless, besides these reports, the relationship between personality and scientific abilities remains poorly explored. In this current study we thus aimed at examining the role of multiple psychopathological dimensions of personality. Indeed, in addition to schizotypy and autistic traits, the personality of scientific students could be characterized by other dimensions, including bipolarity features, anxiety and depression which have been previously linked with elevated schizotypy or autistic dimensions (Claridge \& Blakey, 2009; Simonoff et al., 2012) (Lewandowski et al., 2006; Morvan et al., 2011; Rey, Jouvent, \& Dubal, 2009). These comorbidities are also frequently observed in individuals with autism spectrum disorders (Greenaway \& Howlin, 2010; McPheeters, Davis, Navarre, \& Scott, 2011; Pouw, Rieffe, Stockmann, \& Gadow, 2013). 
Consequently, this study aimed at identifying a typology of scientific students on the basis of personality dimensions related to autism, schizotypy and bipolarity. Using cluster analysis, distinct groups were obtained, which could be differentiated on other variables, including depression symptoms, suicidal ideation and academic level. Therefore these data suggested that the link between autistic traits and ability to succeed in science is not quite independent of other psychopathological dimensions frequently associated with autistic personality traits.

\section{Methods}

\section{Participants}

The sample was composed of 294 students affiliated to French university centers (Blois, Bordeaux, Brest, Lille, Montpellier and Toulouse), aged 18 to $26(M=20.31$; SD=1.95) including 195 female (66.3\%) and 99 male (33.7\%) individuals (Table 1). 96.3\% of participants were French citizens, 1.4\% were from Europe but not France, 1.4\% from Africa and 1\% from North America. Regarding the discipline studied, 85.4\% of participants had a major in life or earth sciences (biology, ecology and geosciences), $5.1 \%$ were involved in healthcare studies (medical or nursing) and $7.5 \%$ in computer sciences or electronics. The majority (54.1\%) of participants were first-year college students and only a small minority $(2.7 \%)$ were graduate students. About the academic performances, only $16.7 \%$ of participants failed during the last semester. For others, the distinction "cum laude" was the most frequent (38.1\%) and "summa cum laude" was granted to only $4.1 \%$ of participants. 


\section{Measures}

The Schizotypal Personality Questionnaire (SPQ) was used to evaluate schizotypal traits (Raine \& Benishay, 1995). This self-report questionnaire was submitted under its short form (SPQ-Brief) constituted of 22 items under the yes/no format (Fonseca-Pedrero, Paino-Pineiro, Lemos-Giraldez, Villazon-Garcia, \& Muniz, 2009). Each item (e.g., "People sometimes find me aloof and distant") is scored 0/1 (no/yes). The internal consistency (Cronbach's $\alpha$ coefficient) was 0.81 in the report by Fonseca-Pedrero et al. Its value was 0.77 in the current study.

Autistic traits were measured using the Autism spectrum Quotient (BaronCohen et al., 2001) in its abridged form (AQ-Short) (Hoekstra et al., 2011). This questionnaire includes 29 items (e.g., "I find social situations easy"). For each statement, participants indicated their extent of endorsement on a 4-point Likert scale ranging from "definitely agree" to "definitely disagree". Responses were scored from 1 to 4, respectively, except for the following items which were inversely scored : 2, 4, 5, 7, 10, $13,14,15,16,22,23,25,26$. The average total score is usually around 56 to 60 in non clinical samples, and a score above 70 suggests the possibility of autism spectrum disorders, whereas individuals with Asperger syndrome display scores above 84 (Hoekstra et al., 2011; Kuenssberg, Murray, Booth, \& McKenzie, 2014). Cronbach' $\alpha$ coefficient was 0.79 in the report by Hoekstra et al. and it was 0.68 in this current study.

The Temperament Evaluation of Memphis, Pisa, Paris and San Diego autoquestionnaire (TEMPS-A) (Akiskal et al., 2005) was used to measure traits of bipolar personality, using the two following subscales: the cyclothymic subscale (12 items; e.g., "my ability to think varies greatly from sharp to dull for no apparent reason") and the hyperthymic subscale (8 items; e.g., "I often get many great ideas"). 
Participants were invited to answer by "yes/no" to each statement and the response is score $1 / 0$, respectively. The cut-off score for each subscale is set at $75 \%$ of affirmative responses (Vohringer et al., 2012). In the work by Akiskal et al., Cronbach' $\alpha$ coefficient was 0.91 and 0.76 for the cyclothymic and the hyperthymic subscales, respectively. In the current study, this coefficient was 0.76 and 0.57 , respectively.

Depressive symptomatology was evaluated using The Centre for Epidemiological Studies-Depression scale (CES-D) (Radloff, 1977). This questionnaire is composed of 23 items. The respondent was asked to indicate how frequently in the past week he or she experienced a particular symptom (e.g., "My sleep has not been good"). Responses were made on a 4-point Likert scale, ranging from 0 , indicating that a symptom was present "rarely or none of the time" to 3 , indicating that a symptom was present "most or all the time". Items 4, 8, 12 and 16 were presented in a positive form ("I was happy") and were thus inversely scored. A score above 23 indicated the presence of a moderate to severe depression. The Cronbach's $\alpha$ coefficient ranged from 0.85 to 0.90 in Radloff's report. In the current study, the internal consistency was high (0.91). The last 3 items of this scale ("I felt life was not worth living", "I felt like hurting myself", and "I felt like killing myself") were treated as a subscale in order to obtain a score of suicidal ideation. In this current study, the Cronbach's $\alpha$ coefficient for this subscale was good ( $\alpha=0.84)$.

This study collected general informations regarding the participants (age, sex, citizenship, discipline, year of study and academic performance during the past semester). Moreover alcohol and cannabis use were assessed with the Alcohol Use Disorders Identification Test (AUDIT) (Gache et al., 2005; Saunders, Aasland, Babor, Delafuente, \& Grant, 1993) and the Cannabis Use Disorder Identification Test-Revised (CUDIT-R) (Adamson et al., 2010). 
Procedure

Participants were contacted through Facebook groups of students in France universities. Questionnaires were submitted using Google Docs and students responded anonymously. To this aim, each questionnaire (SPQ-B, AQ-S etc.) was incorporated into a single questionnaire adapted to Google Docs and composed of different sections corresponding to the original questionnaires. In each section, participants were invited to carefully read the instructions, then to indicate, for each item, their extent of endorsement. Participants who answered less than 95\% of the items were excluded from the study. The procedures were approved by the ethics committee of the research ward.

\section{Statistical analysis}

A cluster analysis was performed to identify distinct profiles of participants on the basis of their scores on the following dimensions: autistic, schizotypal, cyclothymic and hyperthymic. This was achieved by standardizing as z-scores the participants scores for each dimension. A hierarchical cluster analysis was then conducted (Ward's method with squared Euclidean distance). The dendrogram and the agglomeration schedule were used to identify the number of clusters. Then, K-means clustering was used to assign each individual to the identified clusters. Statistical analyses were performed using Statistica 10.

\section{Results}

\section{Descriptive statistics}

$11.22 \%$ of participants obtained a score suggesting an autism spectrum disorder, whilst 3 individuals had a score above 84, indicating the possibility of Asperger 
syndrome (Table 2). Nearly $31 \%$ of respondents displayed a score higher than the cutoff score indicating a moderate to severe depression. Accordingly, around $26 \%$ of individuals expressed suicidal ideations at least once. $20.1 \%$ of participants displayed an hazardous level of drinking, whilst 6.5\% appeared to suffer from a disorder due to cannabis use. It is also noteworthy that we did not observe a significant influence of gender on participant scores, except in the cases of alcohol and cannabis uses which were higher in male students (Table 3).

\section{Cluster analysis}

Based on the dendrogram and the aggregation curve, a four-cluster solution was identified. A discriminant analysis showed clear differences between the four clusters (Wilks' $\lambda=0.093, p<0.001$ ) with $95.9 \%$ of the original group cases correctly classified. The first cluster (n=86, 29.2\% of participants), named "Group with Autistic, Schizotypal and Cyclothymic traits" (GASC), is composed with individuals displaying high scores on these 3 dimensions and with low hyperthymic features (Figure 1). The second group ( $n=67,22.8 \%)$, called "Group with Cyclothymic and Hyperthymic traits" (GCH), is characterized with high level of these 2 dimensions and with reduced autistic and schizotypal features. The $3^{\text {rd }}$ cluster $(n=80,27.2 \%)$ represents the "Group with Low Trait level" (GLT). The $4^{\text {th }}$ group $(n=61,20.8 \%)$ is called "Group with Hyperthymic traits" (GH) and is characterized with high hyperthymic features and with lower scores in other dimensions.

Cluster comparison using ANOVA and post hoc test (Table 4) shows that the group with elevated traits (GASC) displays higher scores of depressive symptomatology $(M=28.5, S D=12.0)$ in comparison with the three other groups $(M=11.7$ to $19.1, S D=5.4$ to 9.2). Moreover, in GASC the score of suicidal ideation $(M=1.6, S D=2.3)$ is much more 
elevated than in all other clusters $(M=0.1$ to $0.5, S D=0.3$ to 1.3$)$. Consequently these data indicate that individuals with high psychopathological traits including autistic features display more frequently a depressive comorbidity, which is likely to interfere with their ability to succeed in science studies.

To assess this assumption, we compared the academic level and performance of the four clusters. Table 4 shows that individuals from GASC display the lowest academic level and results, even though the difference is statistically significant only with the GLT group.

We also compared alcohol and cannabis use in these groups but this did not show significant differences between clusters (Table 4). Finally, we performed for each cluster a Pearson correlation analysis between the depression scores and the autistic and schizotypal dimensions. These correlations were very weak in all clusters (not significant at the level 0.05 ; data not shown), thereby excluding that a putative "negative response bias" explained the association of autistic and schizotypal traits with depressive symptoms.

\section{Discussion}

This work shows that scientific students with specific personality dimensions, including autistic traits, display elevated levels of depressive and suicidal comorbidity. This suggests that autistic features, when associated with other personality traits, interfere negatively with the ability of individuals to succeed in science studies.

Indeed, individuals from the so-called GASC cluster (characterized by elevated levels of autistic, schizotypic and cyclothymic dimensions) displayed scores for depression symptoms higher than the cutoff score for diagnosis of a moderate to severe 
depression. In addition, the suicidal ideation score is remarkably high in this group, at least three times higher than in all other clusters. Consequently, these results suggest that individuals displaying high autistic features along with elevated schizotypy and bipolar dimensions are somewhat impaired in their ability to achieve science studies, which is somewhat confirmed by the fact that these individuals have lower academic level, compared with other groups.

Regarding the validity of this study, it is worthwhile to mention that the sample appears to be similar to other non clinical samples of students described in the literature. For instance, the mean SPQ-B score of 8.47 obtained by participants in this current work is close to the mean value of 9.6 described by Raine \& Benishay (1995). On the same theme, the mean AQ-S score is 61.9 in this study, which is comparable to scores obtained by Dutch or English students ( $M=56.0$ to 59.7; Hoekstra et al., 2011). Similarly, regarding depression symptomatology, the mean score of our sample $(20.36$ in women, 18.56 in men) is very close to scores obtained in French teenagers (20.6 and 18.4, respectively; Chabrol, Rodgers, \& Rousseau, 2007).

Even though earlier reports showed that depressive syndroms are not rare in populations of college students (Tosevski, Milovancevic, \& Gajic, 2010; Vazquez, Otero, \& Diaz, 2012), this current study reveals that participants with schizotypal, autistic and bipolar traits are strongly at risk to develop a depressive pathology along with suicidal tendencies. Consequently, this observation must be put into perspective with previous reports indicating that autistic or schizotypal traits are frequently linked with depression symptoms or anxiety (Cohen \& Matthews, 2010; Fonseca-Pedrero, Paino, Lemos-Giraldez, \& Muniz, 2011; McPheeters et al., 2011; Pouw et al., 2013), comorbidities which led authors to examine whether they could contribute to the 
overlap between autistic and schizotypal personality traits (Mealey, Abbott, Byrne, \& McGillivray, 2014).

It is also noteworthy that, in comparison with the low trait cluster (GLT), the GASC group contains individuals with reduced education level, as well as decreased academic results, even though this latter difference is not statistically significant. This could be an illustration of a link between intensity of psychopathological traits and difficulties during an academic cursus (Tosevski et al., 2010). Consequently, in light of our data, one may reconsider the link between elevated autistic traits and the ability to accomplish science studies, considering that autistic features are thus frequently associated with other psychopathological traits which may, altogether, lead to depression or other comorbidities strongly interfering with the accomplishment of an academic cursus.

A major limit of this study is the uneven ratio between female and male participants in our sample, considering that two thirds of respondents were women. However, Table 3 suggests that this disparity may be a minor issue in this study, as gender did not significantly influence participant scores, except in the cases of alcohol and cannabis use which was higher in male individuals.

In conclusion, this study, albeit descriptive and exploratory, identifies a typology of scientific students on the basis of several psychopathological dimensions, thereby showing that at least schizotypal and bipolar features should be taken into consideration in this population, besides the well-established relation between autistic traits and scientific skills (Baron-Cohen et al., 2001). Indeed, the group of students with the most marked traits displays a preoccupying level of depression signs and suicidal ideation which seems to negatively influence their ability to complete their academic 
cursus. Therefore the link between autistic features and ability to succeed in science is probably not quite independent of other dimensions of personality which, altogether with autistic features, determines a level of morbidity sufficient to impair success in science students.

The authors declare no conflict of interests

Acknowledgements: PR is supported by Inserm 
References

Adamson, S. J., Kay-Lambkin, F. J., Baker, A. L., Lewin, T. J., Thornton, L. et al. (2010). An improved brief measure of cannabis misuse: The Cannabis Use Disorders Identification Test-Revised (CUDIT-R). Drug and Alcohol Dependence, 110, 137143.

Akiskal, H. S., Mendlowicz, M. V., Jean-Louis, G., Rapaport, M. H., Kelsoe, J. R. et al. (2005). TEMPS-A: validation of a short version of a self-rated instrument designed to measure variations in temperament. Journal of Affective Disorders, 85, 45-52.

Baron-Cohen, S., Bolton, P., Wheelwright, S., Scahill, V., Short, L. et al. (1998). Autism occurs more often in families of physicists, engineers, and mathematicians. Autism, 2, 296-301.

Baron-Cohen, S., Wheelwright, S., Burtenshaw, A., \& Hobson, E. (2007). Mathematical talent is linked to autism. Human Nature, 18, 125-131.

Baron-Cohen, S., Wheelwright, S., Skinner, R., Martin, J., \& Clubley, E. (2001). The autismspectrum quotient (AQ): Evidence from Asperger Syndrome/high-functioning autism, males and females, scientists and mathematicians. Journal of Autism and Developmental Disorders, 31, 603-603.

Claridge, G., \& Blakey, S. (2009). Schizotypy and affective temperament: Relationships with divergent thinking and creativity styles. Personality and Individual Differences, 46, 820-826.

Cohen, A. S., \& Matthews, R. A. (2010). Primary and and secondary negative schizotypal traits in a large non-clinical sample. Personality and Individual Differences, 49, 419-424.

Feist, G. J. (2006). How development and personality influence scientific thought, interest, and achievement. Review of General Psychology, 10, 163-182.

Fink, A., Weber, B., Koschutnig, K., Benedek, M., Reishofer, G. et al. (2013). Creativity and schizotypy from the neuroscience perspective. Cognitive, Affective, \& Behavioral Neuroscience, 14, 378-387. 10.3758/s13415-013-0210-6.

Fonseca-Pedrero, E., Paino, M., Lemos-Giraldez, S., \& Muniz, J. (2011). Schizotypal traits and depressive symptoms in nonclinical adolescents. Comprehensive Psychiatry, $52,293-300$.

Fonseca-Pedrero, E., Paino-Pineiro, M., Lemos-Giraldez, S., Villazon-Garcia, U., \& Muniz, J. (2009). Validation of the Schizotypal Personality Questionnaire-Brief Form in adolescents. Schizophrenia Research, 111, 53-60.

Gache, P., Michaud, P., Landry, U., Accietto, C., Arfaoui, S. et al. (2005). The Alcohol Use Disorders Identification Test (AUDIT) as a screening tool for excessive drinking in primary care: Reliability and validity of a French version. Alcoholism-Clinical and Experimental Research, 29, 2001-2007.

Greenaway, R., \& Howlin, P. (2010). Dysfunctional Attitudes and Perfectionism and Their Relationship to Anxious and Depressive Symptoms in Boys with Autism 
Spectrum Disorders. Journal of Autism and Developmental Disorders, 40, 11791187.

Guerin, D. W., Gottfried, A. W., Oliver, P. H., \& Thomas, C. W. (1994). Temperament and school functioning during early adolescence. Journal of Early Adolescence, 14, 200-225.

Hintsanen, M., Alatupa, S., Jokela, M., Lipsanen, J., Hintsa, T. et al. (2012). Associations of temperament traits and mathematics grades in adolescents are dependent on the rater but independent of motivation and cognitive ability. Learning and Individual Differences, 22, 490-497.

Hoekstra, R. A., Vinkhuyzen, A. A. E., Wheelwright, S., Bartels, M., Boomsma, D. I. et al. (2011). The Construction and Validation of an Abridged Version of the AutismSpectrum Quotient (AQ-Short). Journal of Autism and Developmental Disorders, 41, 589-596.

Kuenssberg, R., Murray, A. L., Booth, T., \& McKenzie, K. (2014). Structural validation of the abridged Autism Spectrum Quotient-Short Form in a clinical sample of people with autism spectrum disorders. Autism, 18, 69-75.

Lewandowski, K. E., Barrantes-Vidal, N., Nelson-Gray, R. O., Clancy, C., Kepley, H. O. et al. (2006). Anxiety and depression symptoms in psychometrically identified schizotypy. Schizophrenia Research, 83, 225-235.

MacPherson, J. S., \& Kelly, S. W. (2011). Creativity and positive schizotypy influence the conflict between science and religion. Personality and Individual Differences, 50, 446-450.

McPheeters, M. L., Davis, A., Navarre, J. R., \& Scott, T. A. (2011). Family Report of ASD Concomitant with Depression or Anxiety Among US Children. Journal of Autism and Developmental Disorders, 41, 646-653.

Mealey, A., Abbott, G., Byrne, L. K., \& McGillivray, J. (2014). Overlap between autistic and schizotypal personality traits is not accounted for by anxiety and depression. Psychiatry Research, 219, 380-385.

Morsanyi, K., Primi, C., Handley, S. J., Chiesi, F., \& Galli, S. (2012). Are systemizing and autistic traits related to talent and interest in mathematics and engineering? Testing some of the central claims of the empathizing-systemizing theory. British Journal of Psychology, 103, 472-496.

Morvan, Y., Tibaoui, F., Bourdel, M. C., Loo, H., Akiskal, K. K. et al. (2011). Confirmation of the factorial structure of temperamental autoquestionnaire TEMPS-A in nonclinical young adults and relation to current state of anxiety, depression and to schizotypal traits. Journal of Affective Disorders, 131, 37-44.

Nelson, B., \& Rawlings, D. (2009). How Does It Feel? The Development of the Experience of Creativity Questionnaire. Creativity Research Journal, 21, 43-53.

Nettle, D. (2006). Schizotypy and mental health amongst poets, visual artists, and mathematicians. Journal of Research in Personality, 40, 876-890.

Pouw, L. B. C., Rieffe, C., Stockmann, L., \& Gadow, K. D. (2013). The link between emotion regulation, social functioning, and depression in boys with ASD. Research in Autism Spectrum Disorders, 7, 549-556. 
Radloff, L. S. (1977). The CES-D Scale: A self-report depression scale for research in the general population. Applied Psychological Measurements, 1, 385-401.

Raine, A., \& Benishay, D. (1995). The SBQ-B: A brief screening instrument for schizotypal personality disorder. Journal of Personality Disorders, 9, 346-355.

Rawlings, D., \& Locarnini, A. (2008). Dimensional schizotypy, autism, and unusual word associations in artists and scientists. Journal of Research in Personality, 42, 465471.

Rey, G., Jouvent, R., \& Dubal, S. (2009). Schizotypy, Depression, and Anxiety in Physical and Social Anhedonia. Journal of Clinical Psychology, 65, 695-708.

Rosenman, M. F. (1988). Serendipity and Scientific Discovery. Journal of Creative Behavior, 22, 132-138.

Saunders, J. B., Aasland, O. G., Babor, T. F., Delafuente, J. R., \& Grant, M. (1993). Development of the Alcohol-Use Disorders Identification Test (Audit) - Who Collaborative Project on Early Detection of Persons with Harmful AlcoholConsumption. Addiction, 88, 791-804.

Simonoff, E., Jones, C. R. G., Pickles, A., Happe, F., Baird, G. et al. (2012). Severe mood problems in adolescents with autism spectrum disorder. Journal of Child Psychology and Psychiatry, 53, 1157-1166.

Stoskopf, M. K. (2005). Observation and cogitation: How serendipity provides the building blocks of scientific discovery. ILAR Journal, 43, 332-337.

Tosevski, D. L., Milovancevic, M. P., \& Gajic, S. D. (2010). Personality and psychopathology of university students. Current Opinion in Psychiatry, 23, 48-52.

Vazquez, F. L., Otero, P., \& Diaz, O. (2012). Psychological Distress and Related Factors in Female College Students. Journal of American College Health, 60, 219-225.

Vohringer, P. A., Whitham, E. A., Thommi, S. B., Holtzman, N. S., Khrad, H. et al. (2012). Affective temperaments in clinical practice: A validation study in mood disorders. Journal of Affective Disorders, 136, 577-580.

Wakabayashi, A., Baron-Cohen, S., Wheelwright, S., Goldenfeld, N., Delaney, J. et al. (2006). Development of short forms of the Empathy Quotient (EQ-Short) and the Systemizing Quotient (SQ-Short). Personality and Individual Differences, 41, 929940.

Yewdell, J. W. (2008). How to succeed in science: a concise guide for young biomedical scientists. Part I: taking the plunge. Nature Reviews in Molecular and Cellular Biology, 9, 413-416. 


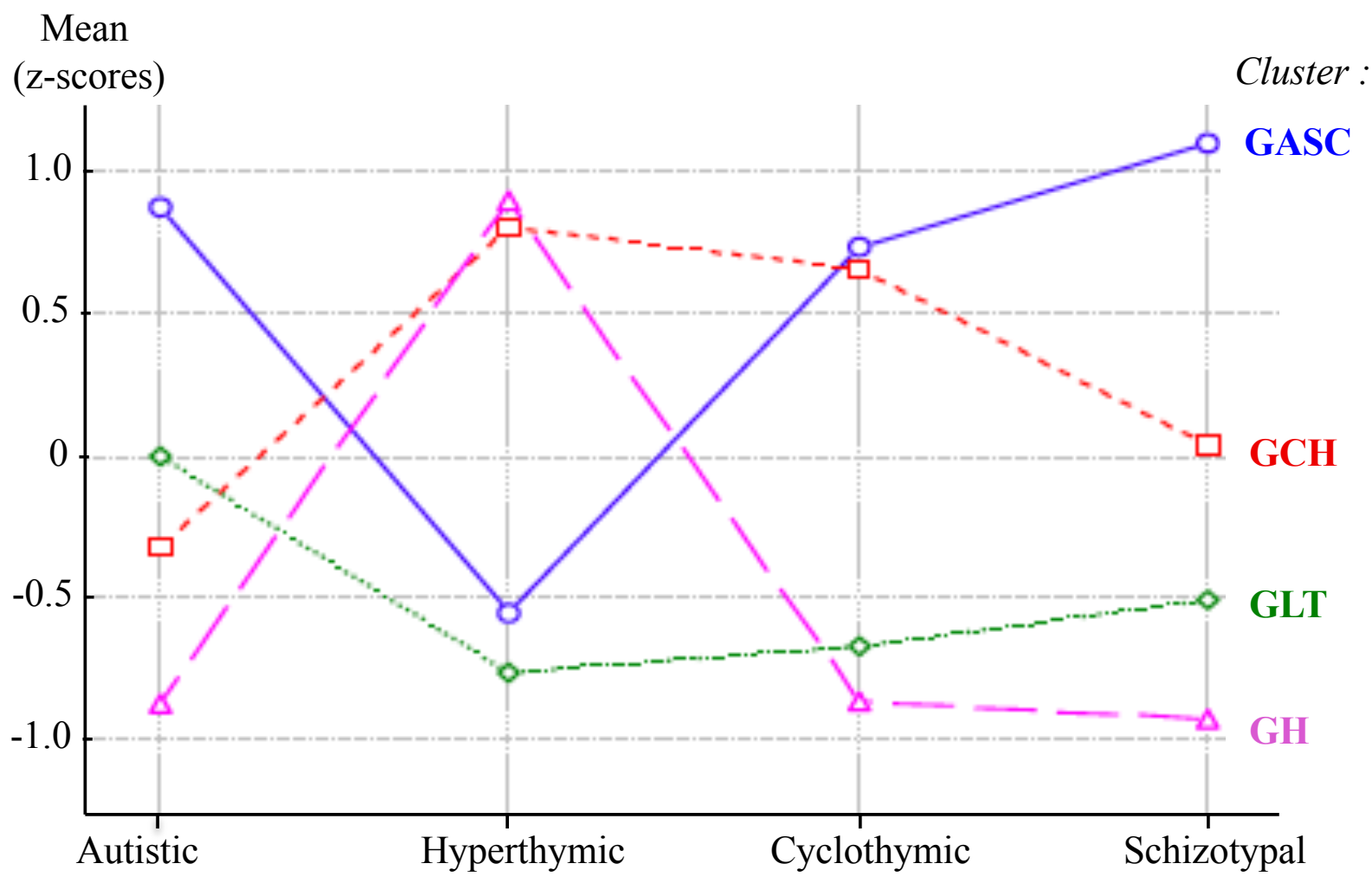

Dimensions

Figure 1. Four-cluster solution (GASC, GCH, GLT and GH) based on scores for the dimensions indicated on the x-axis.

GASC: Group with Autistic, Schizotypal and Cyclothymic traits

GCH: Group with Cyclothymic and Hyperthymic traits

GLT: Group with Low Trait level

GH: Group with Hyperthymic traits 
Table 1

Sample characteristics $(N=294)$

\begin{tabular}{|c|c|c|c|}
\hline Variables & & $\mathrm{n}$ & $\%$ \\
\hline \multirow[t]{2}{*}{ Gender } & - Female & 195 & 66.32 \\
\hline & - Male & 99 & 33.67 \\
\hline Age & $\mathrm{M}=20.31 \quad$ S.D. $=1.95$ & & \\
\hline \multirow[t]{5}{*}{ Country of origin } & - France & 283 & 96.25 \\
\hline & - Europe (except France) & 4 & 1.36 \\
\hline & - Maghreb & 2 & 0.68 \\
\hline & - Africa (except Maghreb) & 2 & 0.68 \\
\hline & - North America & 3 & 1.02 \\
\hline \multirow[t]{2}{*}{ Personal situation } & - Single & 166 & 56.46 \\
\hline & - In a civil partership & 125 & 42.51 \\
\hline \multirow[t]{4}{*}{ Major } & - Life and earth sciences & 252 & 85.42 \\
\hline & - Health & 15 & 5.08 \\
\hline & - Electronics/computer sciences & 22 & 7.48 \\
\hline & - Other & 2 & 0.68 \\
\hline \multirow[t]{6}{*}{ Academic level } & - B.A., first year & 159 & 54.08 \\
\hline & - B.A., second year & 22 & 7.48 \\
\hline & - B.A., final year & 23 & 7.82 \\
\hline & - M.A., first year & 81 & 27.55 \\
\hline & - M.A., second year & 5 & 1.70 \\
\hline & - Ph.D. program & 3 & 1.02 \\
\hline \multirow[t]{5}{*}{ Academic performance } & - Failed & 49 & 16.66 \\
\hline & - Passed & 65 & 22.10 \\
\hline & - Cum laude & 112 & 38.09 \\
\hline & - Magna cum laude & 51 & 17.34 \\
\hline & - Summa cum laude & 12 & 4.08 \\
\hline
\end{tabular}


Table 2

Descriptive statistics of the sample

\begin{tabular}{lccccc}
\hline & Cronbach's & Minimum & Maximum & Mean (S.D.) & \% (n) > cut-off \\
Dimension : & $\alpha$ & score & score & & \\
\hline Schizotypal & 0.77 & 0 & 20 & $8.47(4.23)$ & $8.16(24)$ \\
Autistic & 0.68 & 44 & 88 & $61.88(7.66)$ & $11.22(33)$ \\
Cyclothymic & 0.76 & 0 & 12 & $4.89(3.02)$ & $7.49(22)$ \\
Hyperthymic & 0.57 & 0 & 8 & $3.76(1.93)$ & $10.88(32)$ \\
Depression & 0.91 & 1 & 62 & $19.75(11.12)$ & $30.95(91)$ \\
Suicidal ideation & 0.84 & 0 & 9 & $0.73(1.65)$ & $26.20(77)^{*}$ \\
Alcohol & 0.75 & 0 & 30 & $5.31(4.13)$ & $20.07(59)$ \\
Cannabis & 0.83 & 0 & 23 & $1.71(3.97)$ & $6.46(19)$ \\
\hline
\end{tabular}

* \% (n) of individuals who expressed a suicidal ideation at least once 
Table 3

Mean (S.D.) scores by gender

\begin{tabular}{lcc}
\hline & $\begin{array}{c}\text { Females } \\
n=195\end{array}$ & $\begin{array}{l}\text { Males } \\
n=99\end{array}$ \\
\hline Schizotypal & $8.15(4.11)$ & $9.10(4.42)$ \\
Autistic & $61.56(7.91)$ & $62.50(7.13)$ \\
Cyclothymic & $4.90(2.95)$ & $4.86(3.18)$ \\
Hyperthymic & $3.65(2.03)$ & $3.99(1.71)$ \\
Depression & $20.36(11.27)$ & $18.56(10.80)$ \\
Suicidal ideation & $0.67(1.63)$ & $0.84(1.70)$ \\
Alcohol & $4.84 *(4.02)$ & $6.25 *(4.21)$ \\
Cannabis & $1.31 *(3.14)$ & $2.48 *(5.18)$ \\
\hline
\end{tabular}

* Significative difference between male and female participants (t-test, $p<0.05$ ) 
Table 4

Correlations between variables $(N=294)$

\begin{tabular}{|c|c|c|c|c|c|c|c|c|c|c|}
\hline & Variables & 1 & 2 & 3 & 4 & 5 & 6 & 7 & 8 & 9 \\
\hline 1 & Schizotypal & & & & & & & & & \\
\hline 2 & Autistic & $0.41 *$ & & & & & & & & \\
\hline 3 & Cyclothymic & $0.56^{*}$ & $0.31 *$ & & & & & & & \\
\hline 4 & Hyperthymic & $-0.18 *$ & $-0.38 *$ & -0.01 & & & & & & \\
\hline 5 & Depression & $0.52 *$ & $0.43 *$ & $0.56^{*}$ & $-0.26^{*}$ & & & & & \\
\hline 6 & Suicidal ideation & $0.32 *$ & $0.34 *$ & $0.38 *$ & $-0.12 *$ & $0.78 *$ & & & & \\
\hline 7 & Alcohol & -0.01 & $-0.16^{*}$ & 0.07 & $0.14^{*}$ & 0.03 & 0.03 & & & \\
\hline 8 & Cannabis & 0.05 & -0.05 & 0.04 & $0.12 *$ & 0.04 & 0.07 & $0.34 *$ & & \\
\hline 9 & Academic level & $-0.15^{*}$ & -0.08 & $-0.15^{*}$ & 0.07 & $-0.16^{*}$ & $-0.13 *$ & 0.08 & -0.03 & \\
\hline 10 & Academic performance & -0.06 & 0.04 & -0.09 & 0.04 & $-0.17 *$ & $-0.18 *$ & $-0.16^{*}$ & -0.07 & $0.21 *$ \\
\hline
\end{tabular}


Table 5

Typology of 294 scientific students based on schizotypal, autistic, cyclo- and hyperthymic traits:

Cluster comparison using ANOVA and post-hoc test.

\begin{tabular}{|c|c|c|c|c|c|c|c|c|c|}
\hline \multirow[b]{5}{*}{ Variables } & \multicolumn{8}{|c|}{ Cluster: } & \multirow[b]{5}{*}{$F$} \\
\hline & \multirow{3}{*}{\multicolumn{2}{|c|}{$\begin{array}{c}\text { GASC } \\
\mathrm{n}=86 \\
29.2 \% \\
\end{array}$}} & \multirow{3}{*}{\multicolumn{2}{|c|}{$\begin{array}{c}\mathrm{GCH} \\
\mathrm{n}=67 \\
22.8 \%\end{array}$}} & \multirow{3}{*}{\multicolumn{2}{|c|}{$\begin{array}{c}\text { GLT } \\
n=80 \\
27.2 \%\end{array}$}} & \multirow{3}{*}{\multicolumn{2}{|c|}{$\begin{array}{c}\mathrm{GH} \\
\mathrm{n}=61 \\
20.8 \%\end{array}$}} & \\
\hline & & & & & & & & & \\
\hline & & & & & & & & & \\
\hline & $M$ & S.D. & $M$ & S.D. & $M$ & S.D. & $M$ & S.D. & \\
\hline Schizotypal & $13.15^{\mathrm{a}}$ & 2.78 & $8.61^{\mathrm{a}}$ & 2.55 & $6.32^{\mathrm{a}}$ & 2.56 & $4.54^{\mathrm{a}}$ & 2.79 & $150.09 *$ \\
\hline Autistic & $68.62^{\mathrm{abc}}$ & 6.31 & $59.43^{\text {ad }}$ & 5.91 & $61.83^{\text {be }}$ & 6.05 & $55.13^{\text {cde }}$ & 5.03 & $67.82 *$ \\
\hline Cyclothymic & $7.10^{\mathrm{ab}}$ & 2.52 & $6.87^{\mathrm{cd}}$ & 1.88 & $2.85^{\mathrm{ac}}$ & 1.86 & $2.25^{\mathrm{bd}}$ & 1.76 & $113.13 *$ \\
\hline Hyperthymic & $2.69^{\mathrm{ab}}$ & 1.48 & $5.32^{\mathrm{ac}}$ & 1.28 & $2.28^{\mathrm{cd}}$ & 1.02 & $5.50^{\mathrm{bd}}$ & 1.27 & $126.90^{*}$ \\
\hline Depression & $28.50^{\mathrm{abc}}$ & 12.04 & $19.08^{\text {ad }}$ & 7.44 & $17.05^{\text {be }}$ & 9.18 & $11.69^{\text {cde }}$ & 6.41 & $42.97^{*}$ \\
\hline Suicidal ideation & $1.58^{\mathrm{abc}}$ & 2.29 & $0.54^{\mathrm{a}}$ & 1.34 & $0.46^{\mathrm{b}}$ & 1.30 & $0.08^{\mathrm{c}}$ & 0.28 & $13.20^{*}$ \\
\hline Alcohol & 4.70 & 4.02 & 6.03 & 4.54 & 4.92 & 3.83 & 5.92 & 4.10 & 2.00 \\
\hline Cannabis & 1.54 & 3.93 & 2.13 & 4.25 & 1.47 & 3.75 & 1.79 & 4.07 & 0.40 \\
\hline Academic level & $1.87^{\mathrm{a}}$ & 1.27 & 2.03 & 1.45 & $2.62^{\mathrm{a}}$ & 1.49 & 2.20 & 1.38 & $4.36^{*}$ \\
\hline $\begin{array}{l}\text { Academic } \\
\text { performance }\end{array}$ & 2.58 & 1.09 & 2.76 & 1.04 & 2.81 & 1.08 & 2.63 & 1.05 & 0.78 \\
\hline
\end{tabular}

Note: Means with the same superscript letter are significantly different from each other (Tukey post-hoc test)

$* p<0.05$ 